\title{
A PROSPECTIVE STUDY ON THE ASSESSMENT OF RISK FACTORS FOR TYPE 2 DIABETES MELLITUS IN OUTPATIENTS DEPARTMENT OF A SOUTH INDIAN TERTIARY CARE HOSPITAL: A CASE-CONTROL STUDY
}

\section{SIVAPRASAD PENDYALA ${ }^{1}$, SIDDHARTHA NUTHAKKI ${ }^{1}$, CHARAN VALLABHU ${ }^{1}$, NAVEENBABU KILARU ${ }^{1}$, SIVA R CHALLA ${ }^{1,2}$, RAVINDRABABU PINGILI ${ }^{1,2 *}$}

${ }^{1}$ Department of Pharmacy Practice, KVSR Siddhartha College of Pharmaceutical Sciences, Vijayawada - 520 010, Andhra Pradesh, India ${ }^{2}$ Department of Pharmacology, KVSR Siddhartha College of Pharmaceutical Sciences, Vijayawada - 520 010, Andhra Pradesh, India. Email: ravindrapingili@gmail.com

Received: 01 August 2016, Revised and Accepted: 10 August 2016

\section{ABSTRACT}

Objective: Type 2 diabetes mellitus (T2DM) is the most general type of diabetes. In India, the risk factors (modifiable and non-modifiable) for diabetes are seen more frequently, and there is a lack of perception about this problem. The objective of the study was to assess the incidence and risk factors for T2DM in a south Indian tertiary care hospital.

Methods: A prospective study was conducted on 1161 subjects (with or without T2DM) from November 2014 to April 2015 in General Medicine Department of Dr. Pinnamaneni Siddhartha Institute of Medical Sciences and Research Foundation, Andhra Pradesh, South India. Chi-square test was used to evaluate the incidence of T2DM, and odds ratios were calculated in a univariate logistic regression analysis for risk factors.

Results: T2DM was significantly higher in the subjects of age above 41 years (86.3\%, p<0.0001), married (95.4\%, p=0.002), educators (degree and above, $13.2 \%$, p<0.0001), known family history (50.8\%, p<0.0001), body mass index (BMI) $\left(>25 \mathrm{~kg} / \mathrm{m}^{2}, 58.7 \%\right.$; $\left.<<0.0001\right)$, Government job holders (5.5\%, p<0.0001), business people (12\%, p<0.0001), housewives $(38.3 \%, \mathrm{p}<0.0001)$, high economic status $(34.9 \%$, p<0.0004), preexisting hypertension $(40.2 \%, p<0.0001)$, urban residence $(50.4 \%, p<0.0001)$, physical inactivity $(45.3 \%$, $p<0.001)$, stress $(61.0 \%$, p=0.01), consumption of tea and coffee (daily thrice or more, 6.3\%, p=0.0003), soft drinks (weekly thrice or more, 4\%, p=0.0008), and junk foods (weekly thrice or more $2.6 \%$, $\mathrm{p}=0.025$ ) than non-diabetic subjects. The univariate logistic regression analysis showed that the age (above 41 years), marital status, education, family history, BMI ( $>25 \mathrm{~kg} / \mathrm{m}^{2}$ ), high economic status, co-morbidities (hypertension and thyroid disorders) urban residence, physical inactivity, stress, consumption of tea and coffee (daily thrice or more), soft drinks (weekly thrice or more), and junk foods are the significantly risk factors for T2DM.

Conclusion: This study results suggested that beware of hypertension, thyroids disorders, physical inactivity, stress, soft drinks and junk foods, which are major risk factors of T2DM.

Keywords: Type 2 diabetes mellitus, Glycated hemoglobin, Risk factors, Co-morbidities, Junk foods.

(c) 2016 The Authors. Published by Innovare Academic Sciences Pvt Ltd. This is an open access article under the CC BY license (http://creativecommons. org/licenses/by/4. 0/) DOI: http://dx.doi.org/10.22159/ajpcr.2016.v9i6.14427

\section{INTRODUCTION}

Diabetes mellitus (DM) is metabolic disorder that is characterized by chronic hyperglycemia and associated with microvascular and macrovascular complications with serious morbidity and mortality [1] India, China, and the United States of America (USA) are the three countries with the largest numbers of people with diabetes. India had 33 million patients with diabetes in 2000, a figure that is projected to increase to 79.4 million by 2030 [2]. The number of people with diabetes in the worldwide was 171 million in 2000 and expected to increase to 366 million by 2030 [3,4]. Both genetic and environmental factors are strong risk factors for the development of Type 2 diabetes mellitus (T2DM) [5,6]. Known risk factors of T2DM are overweight $\left(>25 \mathrm{~kg} / \mathrm{m}^{2}\right)$, family history of diabetes, physical inactivity, ethnic predisposition, hypertension, dyslipidemia, cardiovascular disease, history of polycystic ovary syndrome, gestational DM, and macrosomia [7]. Young Indians are at increased 30-fold over 20 years for T2DM along with a concomitant increase in obesity [8]. The South Asian population presents with a number of diverse risk factors for T2DM due to a combination of several genetic and environmental factors [9]. Therefore, this study was planned to assess the risk factors for T2DM in a tertiary care south India hospital.

\section{METHODS}

The present prospective study was conducted at outpatients department of Dr. Pinnamaneni Siddhartha Institute of Medica
Sciences and Research Foundation, Vijayawada, Andhra Pradesh, South India. The study was initiated after approval by the Institutes Ethical Review Committee, KVSR Siddhartha College of Pharmaceutical Sciences (SCOPS), Vijayawada, India. KVSR SCOPS was recognized by All India Council of Technical Education and Pharmacy Council of India, New Delhi, Government of India. The protocol approval number was KVSRSCOPS/IEC/2015/004.

\section{Selection of participants}

The patients of either sex diagnosed with or without T2DM of any duration and willing to participate were included in the study. A total of 1161 patients (415 patients with T2DM and 746 patients without T2DM) were enrolled in the study.

\section{Data collection}

Physicians were requested to report the clinical and biochemical data not exceeding 6 months before the observation. Biochemical parameters (fasting blood glucose, oral glucose tolerance test, and HbA1c values) were derived from the latest laboratory investigation reports documented in the clinical records. The information regarding sociodemographics (age, sex, marital status, education, family history of known hypertension, body mass index (BMI), monthly income, and co-morbid conditions) and lifestyle characteristics (residential area, alcohol consumption, smoking status, food habits, stress at workplace, and physical activity) were collected by interviewing the participant to identify the possible risk factor. All the relevant data were collected 
in a predesigned paper case record form with prior consent of the participant.

\section{Statistical analysis}

Statistical analyses were performed using SPSS version 20 (SPSS Inc., Chicago, IL, USA) and Graph Pad Prism 5.0 software (San Diego, CA). Estimates were expressed as mean \pm standard deviation (SD). One-way analysis of variance or Student's t-test was used to compare groups for continuous variables, and $\chi^{2}$-test was used to compare proportions between the two groups. The univariate logistic regression analysis was used to examine the association between various exposures (age, gender, place of residence, generalized obesity, cigarette smoking alcohol consumption, income status, and literacy level) and outcome (T2DM). $\mathrm{p}<0.05$ was considered significant.

\section{RESULTS}

A total of 1161 subjects ( 415 with T2DM and 746 without T2DM) were included in the study. The biochemical and clinical characteristics of T2DM were presented in Table 1 . Tables 2 and 3 show the sociodemographic and lifestyle characteristics of subjects with and without T2DM, respectively. T2DM was higher in males (48.4\%) when compared to females ( $45.7 \%)$ but statistically not significant $(\mathrm{p}=0.372)$. The mean \pm SD age was $53.6 \pm 10.8(\mathrm{p}<0.0001)$ years in patients with T2DM and $44.6 \pm 15.0$ years in patients without T2DM. Age above 41 years was significantly associated with the T2DM $(\mathrm{p}<0.0001)$ compared to age below 40 years. T2DM was significantly higher in married (95.4\%, $\mathrm{p}=0.002)$ and widowed $(3.4 \%, \mathrm{p}=0.017)$ compared to unmarried (1.2\%). Educators (up to $10^{\text {th }}$ standard, $45.8 \%, \mathrm{p}<0.0001$; above $10^{\text {th }}$ standard, $21.2 \%, \mathrm{p}<0.0001$ ) and family history of known

Table 1: Biochemical and clinical characteristics of patients with T2DM

\begin{tabular}{|c|c|}
\hline Variable & Patients with T2DM $(\mathrm{N}=415)$ \\
\hline \multicolumn{2}{|l|}{ Age (years) } \\
\hline Mean \pm SD & $53.6 \pm 10.8$ \\
\hline $0-20$ & $3(0.7)$ \\
\hline $21-40$ & $132(31.8)$ \\
\hline $41-60$ & $243(58.6)$ \\
\hline Above 61 & $37(8.9)$ \\
\hline \multicolumn{2}{|c|}{ Body weight (kg) } \\
\hline Mean \pm SD & $72.573 \pm 13.224$ \\
\hline \multicolumn{2}{|l|}{ HbA1c (\%) } \\
\hline Mean $\pm S D$ & $7.985 \pm 1.683$ \\
\hline$<7.5$ & $179(43.13)$ \\
\hline $7.5-9$ & $140(33.73)$ \\
\hline$>9$ & $96(23.13)$ \\
\hline \multicolumn{2}{|c|}{ Fasting blood glucose (mg/dL) } \\
\hline Mean \pm SD & $146.348 \pm 63.146$ \\
\hline$<100$ & $95(22.89)$ \\
\hline $100-125$ & $107(25.78)$ \\
\hline$>125$ & $213(51.32)$ \\
\hline \multicolumn{2}{|c|}{ Oral glucose tolerance test (mg/dL) } \\
\hline Mean \pm SD & $196.516 \pm 65.326$ \\
\hline$<140$ & $84(20.24)$ \\
\hline $140-200$ & $161(38.79)$ \\
\hline$>200$ & $170(40.96)$ \\
\hline \multicolumn{2}{|c|}{ Duration of T2DM (years) } \\
\hline$<5$ & $176(42.40)$ \\
\hline $5-10$ & $135(32.53)$ \\
\hline$>10$ & $104(25.06)$ \\
\hline \multicolumn{2}{|c|}{ Frequency of health check-ups } \\
\hline Monthly once & $132(31.8)$ \\
\hline 1-3 months & $266(64.1)$ \\
\hline 4-6 months & $9(2.2)$ \\
\hline$>6$ months & $8(1.9)$ \\
\hline \multicolumn{2}{|c|}{ Following T2DM education } \\
\hline Yes & $348(83.9)$ \\
\hline No & $67(16.1)$ \\
\hline
\end{tabular}

SD: Standard deviation, T2DM: Type 2 diabetes mellitus history $(\mathrm{p}<0.0001)$ are significantly associated with T2DM. T2DM subjects had a greater BMI $\left(>25 \mathrm{~kg} / \mathrm{m}^{2}, \mathrm{P}<0.0001\right)$. High socioeconomic status $(34.9 \%, \mathrm{p}<0.0001)$ was significantly associated with T2DM compared to low economic status. T2DM was significantly higher in the subjects of preexisting co-morbidities (hypertension, $\mathrm{p}<0.0001$; history of cardiovascular diseases, $\mathrm{p}<0.0001$; thyroid disorders, $\mathrm{p}<0.0001)$, urban residence $(50.4 \%, \mathrm{p}<0.0001)$, physical inactivity $(45.3 \%, p<0.0001)$, stress $(61.0 \%, p=0.0108)$, consumption of tea and coffee (daily twice, $5.8 \%, \mathrm{p}=0.0008$; thrice or more, $\mathrm{p}=0.0003$ ), soft drinks (weekly twice, $5.5 \%, p=0.005$; weekly thrice or more, $4.0 \%$, $\mathrm{p}=0.0008$ ), and junk foods (thrice or more in a week, $\mathrm{p}=0.025$ ) than non-diabetic subjects. Private job holders (4.8\%, $\mathrm{p}=0.539)$, history of cardiovascular diseases alone $(2.7 \%, \mathrm{p}=0.104)$, thyroids disorders alone $(2.8 \%, \mathrm{p}=0.115)$, past alcoholic $(2.1 \%, \mathrm{p}=0.401)$, past smokers (3.6\%, $\mathrm{p}=0.609$ ), consumption of tea (once daily, $12.3 \%, \mathrm{p}=0.967$; daily twice, $28.5 \%, p=0.341$ ), coffee (once daily, $4.8 \%, p=0.127$ ), fruits

Table 2: Sociodemographic characteristics of patients with and without T2DM $(\mathrm{N}=1161)$

\begin{tabular}{|c|c|c|c|}
\hline Variable & $\begin{array}{l}\text { Without DM } \\
(\mathrm{N}=746)(\%)\end{array}$ & $\begin{array}{l}\text { With DM } \\
(\mathrm{N}=415)(\%)\end{array}$ & p value ${ }^{a}$ \\
\hline \multicolumn{4}{|l|}{ Gender } \\
\hline Female & $405(54.3)$ & $214(51.6)$ & Ref \\
\hline Male & 341 (45.7) & $201(48.4)$ & 0.372 \\
\hline \multicolumn{4}{|l|}{ Age } \\
\hline Mean \pm SD & $44.6 \pm 15.0$ & $53.6 \pm 10.8$ & $<0.0001$ \\
\hline Below 40 years & $329(44.1)$ & $57(13.7)$ & Ref \\
\hline $41-60$ years & $305(40.9)$ & $255(61.5)$ & $<0.0001$ \\
\hline Above 60 years & $112(15.0)$ & $103(24.8)$ & $<0.0001$ \\
\hline \multicolumn{4}{|l|}{ Marital Status } \\
\hline Unmarried & $34(4.6)$ & $05(1.2)$ & Ref \\
\hline Married & $687(92.0)$ & $396(95.4)$ & 0.002 \\
\hline Widowed & $25(3.4)$ & $14(3.4)$ & 0.017 \\
\hline \multicolumn{4}{|l|}{ Education } \\
\hline Uneducated & $394(52.9)$ & $137(33.0)$ & Ref \\
\hline Up to $10^{\text {th }}$ standard & $251(33.6)$ & $190(45.8)$ & $<0.0001$ \\
\hline Above $10^{\text {th }}$ standard & $47(6.3)$ & $33(8.0)$ & 0.004 \\
\hline Degree & $54(7.2)$ & $55(13.2)$ & $<0.0001$ \\
\hline \multicolumn{4}{|l|}{ Family history of T2DM } \\
\hline No family history & $567(76.0)$ & $204(49.2)$ & Ref \\
\hline Father & $62(8.3)$ & $72(17.3)$ & $<0.0001$ \\
\hline Mother & $67(9.0)$ & $61(14.7)$ & $<0.0001$ \\
\hline Brother and sister & $34(4.5)$ & $46(11.1)$ & $<0.0001$ \\
\hline Father and mother & $16(2.2)$ & $32(7.7)$ & $<0.0001$ \\
\hline \multicolumn{4}{|l|}{ BMI } \\
\hline$<25 \mathrm{~kg} / \mathrm{m}^{2}$ & $538(72.1)$ & $171(41.3)$ & Ref \\
\hline$>25 \mathrm{~kg} / \mathrm{m}^{2}$ & $208(27.9)$ & 244 (58.7) & $<0.0001$ \\
\hline \multicolumn{4}{|l|}{ Nature of work } \\
\hline Daily labor & $292(39.2)$ & 79 (19) & Ref \\
\hline Private job & $62(8.3)$ & $20(4.8)$ & 0.539 \\
\hline Government job & $8(1.0)$ & $23(5.5)$ & $<0.0001$ \\
\hline Retired & $1(0.1)$ & $3(0.7)$ & 0.009 \\
\hline Business & $21(2.9)$ & $50(12)$ & $<0.0001$ \\
\hline House wife & $239(32.0)$ & $159(38.3)$ & $<0.0001$ \\
\hline $\begin{array}{l}\text { Not working any } \\
\text { where }\end{array}$ & $62(8.3)$ & $51(12.3)$ & $<0.0001$ \\
\hline Farmer & $61(8.2)$ & $30(7.2)$ & 0.018 \\
\hline \multicolumn{4}{|l|}{ Socioeconomic status } \\
\hline Low & 617 (82.7) & $270(65.1)$ & Ref \\
\hline High & $129(17.3)$ & $145(34.9)$ & $<0.0001$ \\
\hline \multicolumn{4}{|l|}{ Co-morbidities } \\
\hline No & $576(77.2)$ & $171(41.2)$ & Ref \\
\hline HTN & $99(13.3)$ & $167(40.2)$ & $<0.0001$ \\
\hline History of CVDs & $20(2.7)$ & $11(2.7)$ & 0.104 \\
\hline Thyroid disorders & $18(2.4)$ & $12(2.8)$ & 0.115 \\
\hline HTN and CVDs & $29(3.9)$ & 37 (8.9) & $<0.0001$ \\
\hline HTN and thyroid & $4(0.5)$ & $17(4.1)$ & $<0.0001$ \\
\hline
\end{tabular}

${ }^{a}$ Chi-square test. T2DM: Type 2 diabetes mellitus, DM: Diabetes mellitus, SD: Standard deviation, BMI: Body mass index, HTN: Hypertension, CVD: Cardiovascular disease 
(22.2\%, p=0.506), and junk foods (weekly once, 6.5\%, p=0.093; weekly twice, $2.9 \%, \mathrm{p}=0.444$ ) are not significantly associated with the T2DM.

The univariate logistic regression analysis was performed to determine the odds ratios (OR) for the modifiable and non-modifiable risk factors for T2DM; the results were presented in Table 4. The analysis showed that age (between 41 and 60) years (OR: 4.826, 95\% confidence interval [CI]: 3.481-6.691, p<0.0001), age above 61 years (OR: 5.309, 95\% CI: 3.600-7.826, p<0.0001), married (OR: 3.920, 95\% CI 1.520-10.11, p=0.0091), widowed (OR: 3.808, 95\% CI: 1.212-11.96, $\mathrm{p}=0.033$ ), education (up to $10^{\text {th }}$ standard, OR: $2.177,95 \% \mathrm{CI}: 1.660$ 2.854, p<0.0001; above $10^{\text {th }}$ standard, OR: $2.019,95 \%$ CI: $1.242-3.282$ $\mathrm{p}=0.007$ ), family history (father, OR: 3.228, 95\% CI: 2.217-4.699, $\mathrm{p}<0.0001$; mother, OR: 2.531, 95\% CI: 1.727-3.708, $\mathrm{p}<0.0001$; both

Table 3: Food and life style factors of patients with or without T2DM (N=1161)

\begin{tabular}{|c|c|c|c|}
\hline Variable & $\begin{array}{l}\text { Without DM } \\
(\mathrm{N}=746)(\%)\end{array}$ & $\begin{array}{l}\text { With DM } \\
(\mathrm{N}=415)(\%)\end{array}$ & p value ${ }^{a}$ \\
\hline \multicolumn{4}{|l|}{ Locality } \\
\hline Rural & $473(63.4)$ & $206(49.6)$ & Ref \\
\hline Urban & $273(36.6)$ & $209(50.4)$ & $<0.0001$ \\
\hline \multicolumn{4}{|l|}{ Physical activity } \\
\hline Yes & $534(71.6)$ & 227 (54.7) & Ref \\
\hline No & $212(28.4)$ & $188(45.3)$ & $<0.0001$ \\
\hline \multicolumn{4}{|l|}{ Food habits } \\
\hline Vegetarian & $59(7.9)$ & $104(25)$ & Ref \\
\hline Non-vegetarian & 687 (92.1) & $311(75)$ & $<0.0001$ \\
\hline \multicolumn{4}{|l|}{ Alcohol } \\
\hline No & $616(82.6)$ & $370(89.2)$ & Ref \\
\hline Yes & $109(16.6)$ & $36(8.7)$ & 0.002 \\
\hline $\begin{array}{l}\text { Past alcoholic } \\
\text { (stopped>6 months) }\end{array}$ & $21(2.8)$ & $9(2.1)$ & 0.401 \\
\hline \multicolumn{4}{|l|}{ Smoking } \\
\hline No & $611(81.9)$ & $366(88.2)$ & Ref \\
\hline $0-14$ cigarettes/day & $98(13.1)$ & $28(6.8)$ & 0.0008 \\
\hline >14 cigarettes/day & $16(2.1)$ & $6(1.4)$ & 0.328 \\
\hline Past smoker & $21(2.9)$ & $15(3.6)$ & 0.609 \\
\hline \multicolumn{4}{|l|}{ Stress } \\
\hline No & $349(46.8)$ & $162(39.0)$ & Ref \\
\hline Yes & 397 (53.2) & $253(61.0)$ & 0.0108 \\
\hline \multicolumn{4}{|l|}{ Tea and coffee } \\
\hline No & $110(14.8)$ & $59(14.2)$ & Ref \\
\hline Daily once tea & $96(12.9)$ & $51(12.3)$ & 0.967 \\
\hline Daily twice tea & $265(35.6)$ & $118(28.5)$ & 0.341 \\
\hline $\begin{array}{l}\text { Daily thrice and even } \\
\text { more tea }\end{array}$ & $193(25.9)$ & 57 (13.7) & 0.006 \\
\hline Daily once coffee & $22(3.0)$ & $20(4.8)$ & 0.127 \\
\hline Daily twice coffee & $17(2.3)$ & $20(4.8)$ & 0.030 \\
\hline Daily thrice coffee & $4(0.5)$ & $10(2.4)$ & 0.006 \\
\hline Tea and coffee daily once & $12(1.6)$ & $30(7.2)$ & $<0.0001$ \\
\hline $\begin{array}{l}\text { Tea and coffee daily } \\
\text { twice }\end{array}$ & $13(1.7)$ & $24(5.8)$ & 0.0008 \\
\hline $\begin{array}{l}\text { Tea and coffee daily } \\
\text { thrice and even more }\end{array}$ & $13(1.7)$ & $26(6.3)$ & 0.0003 \\
\hline \multicolumn{4}{|l|}{ Fruits } \\
\hline Yes & $593(79.5)$ & 323 (77.8) & Ref \\
\hline No & $153(20.5)$ & $92(22.2)$ & 0.506 \\
\hline \multicolumn{4}{|l|}{ Soft drinks } \\
\hline No & $524(70.3)$ & $246(59.3)$ & Ref \\
\hline Weekly once & $31(4.1)$ & $27(6.5)$ & 0.022 \\
\hline Weekly twice & $21(2.7)$ & $23(5.5)$ & 0.005 \\
\hline Weekly thrice or more & $10(1.4)$ & $17(4.0)$ & 0.0008 \\
\hline Occasionally & $160(21.4)$ & $102(24.7)$ & 0.038 \\
\hline \multicolumn{4}{|l|}{ Junk foods } \\
\hline No & $575(77.1)$ & $287(69.2)$ & Ref \\
\hline Weekly once & $30(4.0)$ & $24(5.8)$ & 0.093 \\
\hline Weekly twice & $18(2.4)$ & $12(2.9)$ & 0.444 \\
\hline Weekly thrice or more & $8(1.0)$ & $11(2.6)$ & 0.025 \\
\hline Occasionally & $115(15.5)$ & $81(19.5)$ & 0.033 \\
\hline
\end{tabular}

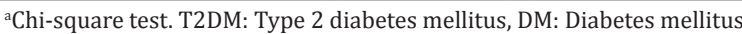

Table 4: Univariate logistic regression analysis for risk factors of T2DM (N=1161)

\begin{tabular}{|c|c|c|}
\hline Variable & OR $(95 \% \mathrm{CI})$ & p value \\
\hline \multicolumn{3}{|l|}{ Gender } \\
\hline Male & $1.116(0.877-1.419)$ & 0.390 \\
\hline \multicolumn{3}{|l|}{ Age } \\
\hline Below 40 years & Ref & \\
\hline $41-60$ years & $4.826(3.481-6.691)$ & $<0.0001$ \\
\hline Above 61 years & $5.309(3.600-7.826)$ & $<0.0001$ \\
\hline \multicolumn{3}{|l|}{ Marital status } \\
\hline Unmarried & Ref & \\
\hline Married & $3.920(1.520-10.11)$ & 0.0019 \\
\hline Widowed & $3.808(1.212-11.96)$ & 0.0332 \\
\hline \multicolumn{3}{|l|}{ Education } \\
\hline Uneducated & Ref & \\
\hline Up to10th standard & $2.177(1.660-2.854)$ & $<0.0001$ \\
\hline Above 10 th standard & $2.019(1.242-3.282)$ & 0.0070 \\
\hline Degree & $2.929(0.919-4.471)$ & $<0.0001$ \\
\hline \multicolumn{3}{|l|}{ Family history of T2DM } \\
\hline No family history & Ref & \\
\hline Father & 3.228 (2.217-4.699) & $<0.0001$ \\
\hline Mother & $2.531(1.727-3.708)$ & $<0.0001$ \\
\hline Brother and sister & $3.760(2.347-6.025)$ & $<0.0001$ \\
\hline Father and mother & $5.559(2.987-10.35)$ & $<0.0001$ \\
\hline \multicolumn{3}{|l|}{ BMI } \\
\hline$<25 \mathrm{~kg} / \mathrm{m} 2$ & Ref & \\
\hline$>25 \mathrm{~kg} / \mathrm{m} 2$ & $3.691(2.867-4.752)$ & $<0.0001$ \\
\hline \multicolumn{3}{|l|}{ Nature of work/profession } \\
\hline Daily labor & Ref & \\
\hline Private job & $1.192(0.679-2.092)$ & 0.559 \\
\hline Government job & $10.63(4.577-24.67)$ & $<0.0001$ \\
\hline Retired & $11.09(1.137-108.1)$ & 0.0342 \\
\hline Business & $8.800(4.991-15.52)$ & $<0.0001$ \\
\hline House wife & $2.459(1.787-3.385)$ & $<0.0001$ \\
\hline Not working anywhere (sedentary) & $3.040(1.946-4.751)$ & $<0.0001$ \\
\hline Farmer & $1.818(1.099-3.006)$ & 0.0268 \\
\hline \multicolumn{3}{|l|}{ Socioeconomic status } \\
\hline Low & Ref & \\
\hline High & $2.569(1.947-3.389)$ & $<0.0001$ \\
\hline \multicolumn{3}{|l|}{ Co-morbidities } \\
\hline No & Ref & \\
\hline HTN & $5.682(4.203-7.683)$ & $<0.0001$ \\
\hline History of CVDs & $1.853(0.870-3.943)$ & 0.127 \\
\hline Thyroid disorders & $2.246(1.060-4.755)$ & 0.045 \\
\hline HTN and CVDs & $4.298(2.567-7.195)$ & $<0.0001$ \\
\hline HTN and thyroid & $14.32(4.752-43.13)$ & $<0.0001$ \\
\hline \multicolumn{3}{|l|}{ Locality } \\
\hline Rural & Ref & \\
\hline Urban & $1.758(1.378-2.242)$ & $<0.0001$ \\
\hline \multicolumn{3}{|l|}{ Physical activity } \\
\hline Yes & Ref & \\
\hline No & $2.086(1.624-2.680)$ & $<0.0001$ \\
\hline \multicolumn{3}{|l|}{ Food habits } \\
\hline Vegetarian & Ref & \\
\hline Non-vegetarian & $0.256(0.181-0.363)$ & $<0.0001$ \\
\hline \multicolumn{3}{|l|}{ Alcohol } \\
\hline No & Ref & \\
\hline Yes & $0.549(0.369-0.818)$ & 0.002 \\
\hline Past alcoholic & $0.713(0.323-1.575)$ & 0.449 \\
\hline Smoking & & \\
\hline No & Ref & \\
\hline $0-14$ cigarettes $/$ day & $0.477(0.307-0.740)$ & 0.0007 \\
\hline$>14$ ciggrates/day & $0.626(0.242-1.675)$ & 0.379 \\
\hline Past smoker & $1.192(0.606-2.343)$ & 0.603 \\
\hline Stress & & \\
\hline No & Ref & \\
\hline Yes & $1.373(1.075-1.753)$ & 0.011 \\
\hline Tea and coffee & & \\
\hline No & Ref & \\
\hline Daily once tea & $0.990(0.622-1.576)$ & 1.000 \\
\hline Daily twice tea & $0.830(0.565-1.218)$ & 0.373 \\
\hline Daily thrice and even more tea & $0.550(0.357-0.848)$ & 0.007 \\
\hline
\end{tabular}

(Contd...) 
Table 4: (Continued)

\begin{tabular}{lll}
\hline Variable & OR (95\% CI) & p value \\
\hline Daily once coffee & $1.695(0.855-3.357)$ & 0.154 \\
Daily twice coffee & $2.663(1.403-5.058)$ & 0.003 \\
Daily thrice coffee & $4.661(1.401-15.51)$ & 0.009 \\
Tea and coffee daily once & $4.661(2.223-9.775)$ & $<0.0001$ \\
Tea and coffee daily twice & $3.442(1.633-7.254)$ & 0.001 \\
Tea and coffee daily thrice and & $3.729(1.784-7.794)$ & 0.0005 \\
even more & & \\
Fruits & & \\
Yes & Ref & \\
No & $1.104(0.824-1.478)$ & 0.548 \\
Soft drinks & & \\
No & Ref & \\
Weekly once & $1.855(1.083-3.177)$ & 0.029 \\
Weekly twice & $2.33(1.267-4.297)$ & 0.007 \\
Weekly thrice or more & $3.621(1.634-8.026)$ & 0.001 \\
Occasionally & $1.358(1.015-1.817)$ & 0.041 \\
Junk foods & & \\
No & Ref & \\
Weekly once & $1.603(0.919-2.793)$ & 0.103 \\
Weekly twice & $1.336(0.634-2.811)$ & 0.437 \\
Weekly thrice and more & $2.755(1.096-6.926)$ & 0.046 \\
Occasionally & $1.411(1.027-1.939)$ & 0.037 \\
\hline
\end{tabular}

T2DM: Type 2 diabetes mellitus, HTN: Hypertension, CVD: Cardiovascular disease, BMI: Body mass index, OR: Odds ratio, CI: Confidence interval

mother and father, OR: 5.556, 95\% CI: 2.987-10.35, p<0.0001; both brother and sister, OR: 3.760, 95\% CI: 2.347-6.025, p<0.0001), BMI (OR: 3.691, 95\% CI: 2.867-4.752, p<0.0001), Government job (OR: 10.63, 95\% CI: 4.577-24.67, p<0.0001), high socioeconomic status (OR: 2.569, 95\% CI: 1.947-3.389, p<0.0001), hypertension (OR: 5.682 , 95\% CI: 4.203-7.683, p<0.0001), thyroid disorders (OR: $2.246,95 \% \mathrm{CI}$ : $1.060-4.755, \mathrm{p}=0.045)$, co-existence of hypertension and thyroid (OR: 14.32, 95\% CI: 4.752-43.13, p<0.0001), urban residence (OR: 1.758, 95\% CI: 1.378-2.248, p<0.0001), physical inactivity (OR: $2.086,95 \%$ CI: 1.624-2.680, p<0.0001), stress (OR: 1.373, 95\% CI: 1.075-1.753, $\mathrm{p}=0.011$ ), consumption of coffee (daily twice, OR: 2.663 , 95\% CI: 1.403 5.053, p=0.003; daily thrice, OR: $4.661,95 \%$ CI: $1.401-15.51, p=0.009$ ), tea and coffee (daily thrice or more, OR: $3.729,95 \%$ CI: $1.784-7.794$, $\mathrm{p}=0.0005$ ), soft drinks (weekly once, OR: 1.855, 95\% CI: 1.083-3.177, p=0.029; weekly twice, OR: $2.33,95 \%$ CI: $1.267-4.279, p=0.007$; weekly thrice or more, OR: 3.621, 95\% CI: 1.634-8.026, $\mathrm{p}=0.001$ ), and junk food (weekly thrice or more, OR: 2.755, 95\% CI: 1.096-6.926, $\mathrm{p}=0.046$ ) were the significant risk factors for T2DM.

\section{DISCUSSION}

India is largely a rural nation and the recent available reports indicate rising prevalence of the disease in the rural areas also [10,11]. In another 20 years, nearly one-fifth of the world's diabetic population will be in India. India faces several major challenges in the management and the prevention of T2DM due to rising prevalence in urban and rural areas, genetic, environmental risk factors, and suboptimal diabetes control. In this study, univariate logistic regression analysis showed that the age (above 41 years), marital status, education, family history, BMI ( $>25 \mathrm{~kg} / \mathrm{m}^{2}$ ), high economic status, co-morbidities (hypertension and thyroid disorders) urban residence, physical inactivity, stress, consumption of tea and coffee (daily thrice or more), soft drinks (weekly thrice or more), and junk foods are the significantly risk factors for T2DM.

Increasing age is significantly associated and the most significant risk factor for T2DM. Shivananda et al. (2014) conducted a study and reported that there was a significant association of age 40-60 years $(\mathrm{n}=147,24.2 \%)$ and above 60 years $(25.6 \%)$ to T2DM [12]. In this study, subjects of age above 40 years are at more risk to T2DM. Another study also agreed that marital status $(n=208,61.2 \%)$ was associated with T2DM [13]. A study conducted by Ravikumar et al. (2011) on prevalence and risk factors of T2DM concluded that educational qualification $(p<0.001)$ was significantly related to the presence of T2DM [2]. Obesity is one of the major risk factors for T2DM. Nandimath et al. (2015) conducted a study on T2DM incidence in contributions of overweight and obesity $(\mathrm{p}<0.001)$ and indicate that T2DM is more attributable to overweight and obesity [14]. Fahad et al. (2015) conducted a study on uncontrolled T2DM prevalence and risk factors among people with T2DM and concluded that housewives and unemployed are at risk for T2DM [13]. Urban people are at more risk to T2DM. Ivan et al. (2016) conducted study on the prevalence of T2DM and concluded that urban population $(\mathrm{p}<0.001)$ are more prone to T2DM than rural population [15]. High socioeconomic status (SES) is associated with T2DM. Lee et al. (2013) conducted study on sex differences in the association between socioeconomic status and T2DM and reported that high SES and T2DM are significantly associated to each other $(n=132$, 28.4\%; p<0.001) [16]. Shivananda et al. (2014) conducted study on association of age to T2DM and reported that hypertension $(n=147$, $28.4 \%$ ) was a more significant risk factor for T2DM [12]. Lifestyle habits and diet plays a major role in T2DM. Tonstad et al. (2013) conducted study on vegetarian diets and incidence of T2DM and identified that vegetarian diets were associated with a substantial and independent reduction in T2DM incidence when compared with non-vegetarians $(n=616,61.6 \%, p<0.0001)$ [17].

Physical inactivity is one of the risk factors for the development of obesity which results in increased risk for T2DM. A study conducted by Sanz et al. (2010) on physical exercise for the prevention and treatment of T2DM and reported that physical exercise can delay progression to T2DM [18]. Alcohol is a risk factor for T2DM, but alcohol consumption $(n=120,9.3 \%, p=0.14)$ was not associated with increased incidence of T2DM [19]. The current study results also suggested that alcohol consumption was not a risk factor for T2DM (OR: 0.549, 95\% CI: 0.369-0.818, p=0.002). Therefore, further studies are needed to evaluate the exact impact of alcohol consumption on risk for T2DM. When compared to people who never smoked, people who are currently smoking are at no risk and people who are past smokers and not smoking in the present $(n=91,7.5 \%, p<0.001)$ are at risk for incidence of T2DM [19]. This study results also suggested that smoking (OR: 0.626, 95\% CI: 0.242-1.675, p=0.379) was not a risk factor for T2DM. There are some studies which showed the association between smoking and T2DM. Therefore, the impact of smoking on incidence of T2DM should be studied in future. A study conducted by Jacqueline et al. (2016) on dietary patterns and T2DM and reported that consumption of unhealthy marketed foods increase the risk of T2DM [20]. In this study, consumption of junk foods is associated with increased incidence of T2DM (weekly thrice or more, OR: $2.755,95 \%$ CI: $1.096-6.926, p=0.046)$. In this study, people taking tea, coffee, and soft drinks are associated with increased risk of acquiring T2DM when compared to people not taking them. In this study, it is also concluded that there is association between frequency of consuming soft drinks, tea, coffee and acquiring T2DM. Ehab et al. (2013) conducted study on soft drinks, fruit juice and vegetable juice intake and risk of DM and concluded that increased consumption of fruits and soft drinks around the world was associated with parallel increase in incidence of T2DM $(\mathrm{p}<0.001)$ [21]. This study results suggested that when compared to persons with no stress, the persons with stress either may be from job/working stress or family stress (OR: 1.373, 95\% CI: 1.075-1.753, $\mathrm{p}=0.011$ ) are at more risk for developing T2DM. A study published by Fahad et al. (2015) reported that patients with stress either from anxiety/depression are at increased risk for developing T2DM when compared to stable patients [13]. Consumption of coffee or both tea and coffee are associated with increased risk for acquiring T2DM. It has also shown that how frequency of consuming tea or coffee or both are contributing to the extent of risk for T2DM. The results from the current study showed that increasing the frequency of coffee intake or both coffee and tea increased the risk for T2DM. Furthermore, there is a most recent study that concluded that drinking tea or coffee cups had an increased risk of acquiring T2DM. Rob et al. (2002) conducted a study on coffee consumption, and risk of T2DM concluded that coffee 
consumption of $\leq 2$ cups/day is at more risk to T2DM ( $\mathrm{n}=125,774,95 \%$, $\mathrm{p}=0.0002$ ) [22]. Therefore, there is a need of further studies to identify and evaluate the exact impact of tea or coffee on the incidence of T2DM.

\section{CONCLUSION}

This study results indicated that increased age, BMI $\left(>25 \mathrm{~kg} / \mathrm{m}^{2}\right)$, urban residence, daily labors, housewives, high economic status, hypertension, physical inactivity, stress, tea, coffee, junk foods, soft drinks, and known family history are the major risk factors for T2DM.

\section{ACKNOWLEDGMENTS}

This study was supported by Siddhartha Academy of General and Technical Education (SAGTE). The authors are grateful to the physicians of Dr. Pinnamaneni Siddhartha Institute of Medical Sciences and Research Foundation, Vijayawada, Andhra Pradesh for providing necessary information. The authors thank N. Venkateswarlu, President and P. Lakshmana Rao, Secretary of SAGTE for providing necessary facilities.

\section{REFERENCES}

1. Murad MA, Abdulmageed SS, Iftikhar R, Sagga BK. Assessment of the common risk factors associated with type 2 diabetes mellitus in jeddah. Int J Endocrinol 2014;2014:616145.

2. Ravikumar P, Bhansali A, Ravikiran M, Bhansali S, Walia R, Shanmugasundar G, et al. Prevalence and risk factors of diabetes in a community-based study in North India: The Chandigarh Urban Diabetes Study (CUDS). Diabetes Metab 2011;37(3):216-21.

3. Abougalambou SS, Abougalambou AS. A study evaluating prevalence of hypertension and risk factors affecting on blood pressure control among type 2 diabetes patients attending teaching hospital in Malaysia. Diabetes Metab Syndr 2013;7(2):83-6.

4. Mohan V, Mathur P, Deepa R, Deepa M, Shukla DK, Menon GR, et al. Urban rural differences in prevalence of self-reported diabetes in India - the WHO-ICMR Indian NCD risk factor surveillance. Diabetes Res Clin Pract 2008;80(1):159-68.

5. Ning F, Pang Z, Laatikainen T, Gao W, Wang S, Zhang L, et al. Join effect of family history of diabetes with obesity on prevalence of type 2 diabetes mellitus among Chinese and Finnish men and women. Can J Diabetes 2013;37(2):65-71.

6. Sanz C, Gautier JF, Hanaire H. Physical exercise for the prevention and treatment of type 2 diabetes. Diabetes Metab 2010;36(5):346-51.

7. Brian KA, Pamala AJ, Robin LC, Wayne AK, Michael EE, Bradley RW, et al. Koda-Kimble and Young's Applied Therapeutics: The Clinica use of Drugs. $10^{\text {th }}$ ed. Philadelphia, PA, United States of America: Lippincott Williams \& Wilkins-Wolters Kluwer; 2013. p. 1223-300.
8. Zargar AH, Wani AA, Laway BA, Masoodi SR, Wani AI, Bashir MI, et al. Prevalence of diabetes mellitus and other abnormalities of glucose tolerance in young adults aged 20-40 years in North India (Kashmir Valley). Diabetes Res Clin Pract 2008;82(2):276-81.

9. Islam SM, Alam DS, Wahiduzzaman M, Niessen LW, Froeschl G, Ferrari U, et al. Clinical characteristics and complications of patients with type 2 diabetes attending an urban hospital in Bangladesh. Diabetes Metab Syndr 2015;9(1):7-13.

10. Gupta R, Misra A. Type 2 diabetes in India: Regional disparities. Br J Diabetes Vasc Dis 2007:7:12-6.

11. Joshi SR, Das AK, Vijay VJ, Mohan V. Challenges in diabetes care in India: Sheer numbers, lack of awareness and inadequate control. J Assoc Physicians India 2008;56:443-50.

12. Nayak BS, Sobrian A, Latiff K, Pope D, Rampersad A, Lourenço K, et al. The association of age, gender, ethnicity, family history, obesity and hypertension with type 2 diabetes mellitus in Trinidad. Diabetes Metab Syndr 2014;8(2):91-5.

13. Siddiqui FJ, Avan BI, Mahmud S, Nanan DJ, Jabbar A, Assam PN. Uncontrolled diabetes mellitus: Prevalence and risk factors among people with type 2 diabetes mellitus in an Urban District of Karachi, Pakistan. Diabetes Res Clin Pract 2015;107(1):148-56.

14. Nandimath VA, Swamy CS, Nandimath SA, Jatti G, Jadhav S. Evaluation of certain risk factors of type 2 diabetes mellitus: A casecontrol study. Int J Med Sci Public Health 2016;5:1334-9.

15. Dedov I, Shestakova M, Benedetti MM, Simon D, Pakhomov I, Galstyan G. Prevalence of type 2 diabetes mellitus (T2DM) in the adult Russian population (NATION study). Diabetes Res Clin Pract 2016;115:90-5.

16. Lee DS, Kim YJ, Han HR. Sex differences in the association between socio-economic status and type 2 diabetes: Data from the 2005 Korean National Health and Nutritional Examination Survey (KNHANES). Public Health 2013;127(6):554-60.

17. Tonstad S, Stewart K, Oda K, Batech M, Herring RP, Fraser GE Vegetarian diets and incidence of diabetes in the Adventist Health Study-2. Nutr Metab Cardiovasc Dis 2013;23(4):292-9.

18. Sanz C, Gautier JF, Hanaire H. Physical exercise for the prevention and treatment of type 2 diabetes. Diabetes Metab 2010;36(5):346-51.

19. Christy C, Kathleen B, Nahla H, Shafika A, Abla MS. Prevalence, correlates and management of type 2 diabetes mellitus in Lebanon: Findings from a national population-based study. Diabetes Res Clin Pract 2014;105(3):408-15.

20. Reeds J, Mansuri S, Mamakeesick M, Harris SB, Zinman B, Gittelsohn $\mathrm{J}$, et al. Dietary patterns and type 2 diabetes mellitus in a first nations community. Can J Diabetes 2016;40(4):304-10.

21. Eshak ES, Iso H, Mizoue T, Inoue M, Noda M, Tsugane S. Soft drink, $100 \%$ fruit juice, and vegetable juice intakes and risk of diabetes mellitus. Clin Nutr 2013;32(2):300-8

22. van Dam RM, Feskens EJ. Coffee consumption and risk of type 2 diabetes mellitus. Lancet 2002;360(9344):1477-8 